\title{
Comment on: "Completion pancreatectomy or a pancreas- preserving procedure during relaparotomy for pancreatic fistula after pancreatoduodenectomy: a multicentre cohort study and meta-analysis"
}

\author{
Régis Souche, Jean-Michel Fabre \\ Department of Oncologic and Minimally Invasive Digestive Surgery, Hospital Saint Eloi, University Hospital of Montpellier, Montpellier, France \\ Correspondence to: Regis Souche. Department of Oncologic and Minimally Invasive Digestive Surgery, Hospital Saint Eloi, University Hospital of \\ Montpellier, 80 Avenue Augustin Fliche, Montpellier 34295, France. Email: fr-souche@chu-montpellier.fr. \\ Comment on: Groen JV, Smits FJ, Koole D, et al. Completion pancreatectomy or a pancreas-preserving procedure during relaparotomy for pancreatic \\ fistula after pancreatoduodenectomy: a multicentre cohort study and meta-analysis. Br J Surg 2021;108:1371-9.
}

Submitted Jan 01, 2022. Accepted for publication Jan 12, 2022.

doi: $10.21037 / \mathrm{hbsn}-22-2$

View this article at: https://dx.doi.org/10.21037/hbsn-22-2

We read with great interest the recently published article of Groen et al. from the Dutch Pancreatic Cancer Group (1) appeared on British fournal of Surgery. The authors compared salvage completion pancreatectomy with a pancreas-preserving procedure in patients undergoing relaparotomy for severe pancreatic fistula after pancreatoduodenectomy (PD). This retrospective multi center cohort study included patients who underwent relaparotomy for pancreatic fistula after PD from 20052018 and provided a systematic review with a metaanalysis on postoperative death. In the literature, large retrospective studies dedicated to this question are rare and no randomized study is available to date.

The authors included 4,877 PD from 9 centers in the analysis. From them, $786(16 \%)$ developed a pancreatic fistula grade $\mathrm{B} / \mathrm{C}$ and $162(3 \%)$ underwent a relaparotomy. Of these patients, $36(22 \%)$ underwent a completion pancreatectomy and $126(78 \%)$ a pancreas-preserving procedure. Mortality was higher after completion pancreatectomy $(56 \%$ vs. $32 \% ; \mathrm{P}=0.009)$ with odds ratio (OR) of 2.55 [95\% confidence interval (CI): 1.07-6.08] after adjusting for patients and pre-reoperation data. The proportion of additional reoperations was not different between groups (64\% vs. 67\%; $\mathrm{P}=0.756)$. The metaanalysis including 33 studies (745 patients) found an association between salvage completion pancreatectomy and mortality $(\mathrm{OR}=1.99 ; 95 \% \mathrm{CI}: 1.03-3.84)$. The authors concluded that a pancreas-preserving procedure seems preferable to completion pancreatectomy in patients in whom a relaparotomy is required for severe pancreatic fistula after PD.

The authors should be acknowledged as they investigated a controversy topic and present interesting results for our clinical practice and junior surgeons learning. While the authors have suggested a benefit of a first step-up approach by percutaneous drainage (compared to a reoperation) in patients with severe pancreatic fistula (2), they propose in this work to determine what is the best surgical strategy when reoperation is mandatory $(20 \%$ of patients with grade $\mathrm{B} / \mathrm{C}$ pancreatic fistula in this study, $17-37 \%$ in the literature).

Indeed, completion pancreatectomy may seem an attractive strategy in the case of a patient with severe pancreatic fistula after failure of less invasive techniques such as percutaneous drainage. If this strategy allows to remove the pancreaticojejunal or pancreaticogastric anastomosis in order to stop the vicious circle of septic and/ or hemorrhagic complications, completion pancreatectomy is probably easier said than done. Completion pancreatectomy could induce a "second hit" phenomenon for the patient who could benefit from less aggressive strategies similar to damage control approaches $(3,4)$. This "second hit" effect is illustrated in the present study by a significant mortality (56\%) and an Acute Physiology 
and Chronic Health Evaluation II (APACHE II) score 24 hours after reoperation, significantly higher in the "completion pancreatectomy" group (18 vs. 15; $\mathrm{P} \leq 0.001)$. Likewise, descriptive data on the rate of splenectomy and complications such as digestive perforation and ischemic complications (gastric, colic) are not provided in this study. Conversely, a conservative strategy for pancreatic anastomosis (22 different strategies in this study) is probably less aggressive for the patient but could expose him to one or more reoperations linked to a remnant vicious cycle of sepsis and bleeding. The remnant pancreas being preserved with or without anastomosis, the vessels (especially the arteries) remain potentially exposed to pancreatic fistula and fluid collections. However, this strategy is probably mindful for the principles of "damage control" in these particular patients, in septic and/or hemorrhagic shock.

In this retrospective study, the authors inevitably encountered significant differences in the intrinsic criteria between their two samples (arm? strategies? options?), raising a probable selection bias in a very heterogeneous cohort of patients and surgeons. In fact, the two groups differed on (I) the age which were higher in the "completion pancreatectomy" group and on (II) the existence of multiple organ failure which were more common previous to completion pancreatectomy. These differences could explain a higher mortality rate in the completion pancreatectomy group. Due to the limited size of this last group ( $n=36)$, it was difficult to consider matching by propensity score. Therefore, the authors performed a multivariate analysis on the primary endpoint "mortality" with an adjustment for the variables gender, age, body mass index (BMI), American Society of Anesthesiologists (ASA) score, previous reoperations and organ failure before reoperation and showed that a completion pancreatectomy remained significantly associated with postoperative mortality.

To try to overcome the limits of this first analysis, the authors carried out a sensitivity analysis over period allowing to confirm that: (I) the place of a completion pancreatectomy was constant over time over four 3-year periods from 2005 to 2018 and that (II) the mortality rate was systematically higher in the "completion pancreatectomy" group compared to the "pancreaspreserving procedure" group. The authors also provide a systematic review with meta-analysis showing that completion pancreatectomy was associated with a higher mortality compared to the pancreas-preserving procedure. The limitations described above also concern the studies included in this meta-analysis and make it difficult to interpret the "mortality" event.

One of the strengths of this work is that no difference between the two groups was demonstrated on the rates of use of percutaneous drainage, subsequent reoperation, postreoperation hemorrhage and the mean duration of hospital stay in survivors. These data suggest that there is few risk of undertreatment for the patient when a pancreatic preservation strategy is decided. Conversely, it also suggests that we can over-treat a patient by performing a completion pancreatectomy which would expose him to a risk of increased mortality.

In conclusion, these results must be interpreted with caution given the probable confounding factors not considered in this retrospective study. Indeed, time between $\mathrm{PD}$ and reoperation, data concerning blood loss during reoperation and antibiotic therapy protocols are not reported. The results that we could obtain by performing an early standardized completion pancreatectomy immediately after the diagnosis of severe pancreatic fistula in patients with any or few comorbidities remain probably interesting (5). Further studies including a large cohort of completion pancreatectomy are required to identify risk factors of postoperative mortality. A study randomizing a "completion pancreatectomy" vs. a "pancreas-preserving procedure" has not yet been proposed and seems difficult to consider given the low incidence of this situation, the emergency context, and the multiple preservation strategies adopted by surgeons. In the subgroup of patients with catheter drainage-resistant severe pancreatic fistula, the best surgical strategy is probably a tailored strategy according to the patient's clinical status and especially, the time between PD and reoperation conditioning the intraoperative conditions in these severely-ill patients. This study also raises the question of the prevention of these serious complications/cases by proposing, for example, a total PD with islet autotransplantation in patients at high risk of severe pancreatic fistula $(6,7)$. They do not consider also the mortality/morbidity after total pancreatectomy related to brittle diabetes. In patients with impaired endocrine function (borderline diabetes), probably the total pancreatectomy could be advocated.

\section{Acknowledgments}

Funding: None.

\section{Footnote}

Provenance and Peer Review: This article was commissioned 
by the editorial office, Hepatobiliary Surgery and Nutrition. The article did not undergo external peer review.

Conflicts of Interest: Both authors have completed the ICMJE uniform disclosure form (available at https://hbsn. amegroups.com/article/view/10.21037/hbsn-22-2/coif). The authors have no conflicts of interest to declare.

Ethical Statement: The authors are accountable for all aspects of the work in ensuring that questions related to the accuracy or integrity of any part of the work are appropriately investigated and resolved.

Open Access Statement: This is an Open Access article distributed in accordance with the Creative Commons Attribution-NonCommercial-NoDerivs 4.0 International License (CC BY-NC-ND 4.0), which permits the noncommercial replication and distribution of the article with the strict proviso that no changes or edits are made and the original work is properly cited (including links to both the formal publication through the relevant DOI and the license). See: https://creativecommons.org/licenses/by-nc-nd/4.0/.

\section{References}

1. Groen JV, Smits FJ, Koole D, et al. Completion pancreatectomy or a pancreas-preserving procedure

Cite this article as: Souche R, Fabre JM. Comment on: "Completion pancreatectomy or a pancreas-preserving procedure during relaparotomy for pancreatic fistula after pancreatoduodenectomy: a multicentre cohort study and metaanalysis". HepatoBiliary Surg Nutr 2022;11(1):94-96. doi: 10.21037/hbsn-22-2 during relaparotomy for pancreatic fistula after pancreatoduodenectomy: a multicentre cohort study and meta-analysis. Br J Surg 2021;108:1371-9.

2. Smits FJ, van Santvoort HC, Besselink MG, et al. Management of Severe Pancreatic Fistula After Pancreatoduodenectomy. JAMA Surg 2017;152:540-8.

3. Tschoeke SK, Hellmuth M, Hostmann A, et al. The early second hit in trauma management augments the proinflammatory immune response to multiple injuries. J Trauma 2007;62:1396-403; discussion 1403-4.

4. Lessing Y, Pencovich N, Nevo N, et al. Early reoperation following pancreaticoduodenectomy: impact on morbidity, mortality, and long-term survival. World J Surg Oncol 2019;17:26.

5. Garnier J, Ewald J, Marchese U, et al. Standardized salvage completion pancreatectomy for grade $\mathrm{C}$ postoperative pancreatic fistula after pancreatoduodenectomy (with video). HPB (Oxford) 2021;23:1418-26.

6. Balzano G, Maffi P, Nano R, et al. Extending indications for islet autotransplantation in pancreatic surgery. Ann Surg 2013;258:210-8.

7. Pattou F. Efficacy and Safety of TPIAT for Resectable Adenocarcinoma of the Pancreas Region at High Risk of Postoperative Fistula (TPIAT-01)-NCT05116072. Clinicaltrialgov. 2021. Available online: https://www. clinicaltrials.gov/ct2/show/NCT05116072 